\title{
Evidence-Based Practice among Critical Care Nurse's/Midwives in Qatar
}

\section{Badriya Al-Lenjawi, Jibin Kunjavara* ${ }^{\circledR}$, Nesiya Hassan, Kamaruddeen Mannethodi ${ }^{\mathbb{D}}$, Ederlie Martinez, George V. Joy, Kalpana Singh*}

Department of Nursing and Midwifery Research, Hamad Medical Corporation Doha, Doha, Qatar

Email: Blenjawi@hamad.qa, *JKunjavara@hamad.qa, NHASSAN8@hamad.qa,KMannethodi@hamad.qa, EPitiquen@hamad.qa, GJoy1@hamad.qa, *KSingh1@hamad.qa

How to cite this paper: Al-Lenjawi, B., Kunjavara, J., Hassan, N., Mannethodi, K., Martinez, E., Joy, G.V. and Singh, K. (2022) Evidence-Based Practice among Critical Care Nurse's/Midwives in Qatar. Open Journal of Nursing, 12, 42-59.

https://doi.org/10.4236/ojn.2022.121004

Received: November 7, 2021

Accepted: January 24, 2022

Published: January 27, 2022

Copyright ( 2022 by author(s) and Scientific Research Publishing Inc. This work is licensed under the Creative Commons Attribution International License (CC BY 4.0).

http://creativecommons.org/licenses/by/4.0/ (c) (i) Open Access

\begin{abstract}
Background: Successful implementation of evidence-based research into clinical practice was determined by four core elements, self-belief, the nature and level of evidence, the conductive context into which the study is to be implemented, and organizational factors facilitating the process. Aim: The current study aimed to examine barriers influencing evidence-based practice among critical care nurses in QATAR. Methods: A cross-sectional survey was utilized for the study resulting in data collected from 278 nurses during the period of Feb-2021 to March 2021 using the Barriers to Research Utilization Scale (BTRUS). The BTRUS consisted of data on various information sources utilized by nurses for support in practice, potential barriers for evidence-based practice, and perceived skills on applying research-based evidence. Result: The most significant organizational barriers were lack of time, lack of empowerment to change practice, lack of support from colleagues in implementing research evidence, and lack of access to research articles. Self-perceived barriers were irrelevance of research evidence to current practice, studies having methodological flaws, skepticism about research findings, a large amount of research evidence, and inability to understand statistics. The Nurse's age, years of nursing practice, academic attainment, and organizational position influenced self-reported barriers and utilization of sources of Evidence. Conclusion: Organizational support, improved self-belief, and evidencebased practice expertise may reduce barriers to implementing research evidence in clinical Practice.
\end{abstract}

\section{Keywords}

EBP—Evidence Based Practice, CNS/CMS—Clinical Nurse/Midwife Specialists 


\section{Introduction and Background}

Evidence-Based Practice (EBP) in Nursing is a framework for clinical practice that integrates the best available scientific Evidence with a Nurse's expertise and the patient's preferences to decide about the health care of individual patients [1] [2] [3]. Nurses and midwives are the largest group of health care providers and have a crucial role in ensuring better services to promote health care. Nurses are expected to provide high-quality, safe, effective, fast, and patient-oriented care [4]. Knowledge of research and evidence-based care has become an integral part of nursing practice; this knowledge has resulted in the extended role of nurses, including advanced nurse practitioners and clinical nurse specialists [5].

The Institute of Medicine stressed the importance of practicing care be based on scientific Evidence and stated that, by the 2020s, approximately $90 \%$ of all decisions related to patient care should be based on Evidence [6]. Despite increasing availability of research findings and broad consensus on the importance of its benefits in the nursing discipline, using them in nursing practice remains, at best, slow and arbitrary. This "gap between research and practice" is a worldwide phenomenon, resulting in suboptimal care being delivered to patients. To achieve this, identifying barriers and facilitators of evidence-based practices would be a key strategy [7] [8] [9].

Robust Evidence is considered a crucial factor in Critical Care Units (CCUs), and it's essential to keep up with new Evidence to provide high-quality-costeffective nursing care [8]. Inadequate utilization of research findings in clinical areas leads to negative consequences, including ineffective use of resources, unsatisfactory patient outcomes, negative impact on quality, the length of stay, and increased cost and possible potential health complications [10] [11].

Therefore, an abundant amount of data shows that patients who received care based on the latest evidence experienced 28\% improvements in behavioural knowledge and physiological and psychosocial outcomes than patients whose care was based on traditional practice [11]. Although Nurses generally report positive attitudes and beliefs towards EBP, there are many barriers to implementing EBP, including individual and organizational barriers [12]. These include lack of familiarity, lack of time, heavy workload, lack of experienced staff in EBP resources [1] [11] [13].

According to the researcher's knowledge, limited research studies were conducted on Barriers to EBP in critical care nurses and Clinical Nurses/Midwife Specialists in the middle east region, including Qatar. They have a crucial role in synthesizing Evidence and supporting the organization to implement EBP in Clinical Practices. In accordance with the paradigm shift of national health strategy, HMC encourages traditional nursing practices based on intuition to clinically proven [12]. HMC focus on developing a research culture on Nurses, particularly in critical care and CNS in the Initial stage. Accordingly, the present study aimed to find out the barriers influencing evidence-based practice application among critical care nurses. 


\section{Methods}

\subsection{Design and Objectives}

Quantitative Cross-sectional design adopted for this study involving all critical care Nurses and CNS and CMS working in HMC. Self-reported questionnaires were designed to fulfil the following research objectives, i.e., the barriers of evidence-based practices among essential nurses of care and Clinical Nurse Specialists; the association between demographic variables (age, gender, Marital status, academic qualifications experience, job Position) with barriers to EBP; the factors to facilitate to implement EBP.

\subsection{Study Settings and Sampling}

The study was conducted in Hamad Medical Corporation, the primary health care provider in Qatar. The nursing research department conducted a clinical research workshop on critical care nurses in collaboration with Guy's and St. Thomas Hospital, NHS trust UK in 2019. The Nursing Research team identified the gap in research knowledge and practiced among critical care nurses through the clinical research workshop. So this study enrolled all essential nurses of care and CNS working in selected facilities under HMC like Hamad General Hospital, Alwakrah Hospital, Heart hospital, WWRC, Cuban Hospital, Hazmmaebarik general hospital, Ambulatory Care Center, Communicable disease center, $\mathrm{Ru}$ mailah Hospital, and Alkhor Hospital. The total study period was seven months, and the data were collected for two months (Feb-2021 to March 2021). The data was collected from the participants through the online survey. The total population was nearly 1000, including all critical care nurses and Clinical nurses/Midwife specialists in HMC. The calculated sample size was 278 based on $95 \%$ of the confidence interval and 5\% marginal error. The research team winds up the data collection when it was reached 289 responses. All the critical care Nurses, CNS, and CMS working in different facilities of HMC were included, whereas newly hired nurses are crucial to adapt to HMC culture, improving clinical skills and targeting to complete their clinical competency were excluded.

\subsection{Instruments and Data Collection}

The data were collected by using validated 5 points "Barriers to Research utilization scale (BTRUS) scale" developed by S. Funk et al. [14] with their permission. The scale was modified to barriers to Evidence-Based Practice Questionnaire (EBPQ) based on pilot study responses. The scale has three different sessions. First Session consisted of 6 demographic questions of the participants. The second Session includes 31 questions addressed to barriers to EBP.

The first eight questions were focused on a nurse-related barrier, and the second 11 questions addressed the research-related barrier, and the last 12 questions were on organizational barriers.

The Third section comprises two open-ended questions about the additional barriers and facilitating factors to Evidence-Based Practice. The measurement of 
the scale was categorized and scored as [0-No extent, 1-little Extent, 2Moderate extent, 3-Great Extent, 4-No opinion]. Moderate extent and great extent score were considered barriers, whereas No Opinion excluded from the data analysis.

\subsection{Data Collection Procedure}

The electronic version of the questionnaire was circulated to the critical care Nurses and CNS through the nursing email group with the help of Nursing leaders of the Critical care department and HMC workforce. "Microsoft Forms" was used as a platform to create the online survey link. The purpose of the study was clearly mentioned to the participants through the Information sheet along with an email. The subject's participation in the study was completely voluntary and anonymous. Each participant took below 15 minutes to complete the questionnaire; also, the completion of the questionnaire indicates consent to participate in the study. The participants were allowed to clarify their doubts and concerns regarding this study, and it was explained by the research team members through email and telephone. Two reminders were sent to the participants to encourage their participation in the study. The survey link was opened for a 2-month period, and no further follow-up or contact was required with the participants.

\subsection{Statistical Analysis}

Quantitative data were coded and analyzed using STATA 15.01 software. The data was obtained through descriptive statistics of means, standard deviations, and frequencies. Analysis was performed as follows. For each subscale, the mean scores were added, and then the sum was divided by the number of items in the subscale. For the continuous variables to check the statistical association between demographic variables and Scores, t-test and one-way ANOVA tests were used. The comparison of categorical variables was made by the chi-squared test.

\subsection{Ethical Consideration}

This study was conducted in full conformance with principles of the "Belmont Report." The Permission letter was obtained from the Institutional Review Board (MRC-01-20-1059) of HMC before data collection.

\section{Results}

The questionnaire was answered by 289 participants. All participants fully completed the barrier scale questionnaire. Table 1 presents the distribution of demographic characteristics of the participants. The sample included $76.8 \%$ women. The average age was 34.3 years $(S D=8.2)$, with a range of 20 - 56 years. Regarding marital status, 225 (77.9\%) were married; 1 (0.3\%) were divorced/ widow. Mostly had completed bachelor's degree 196 (67.8\%) and 61 (21.1\%) had completed masters/ Ph.D. and $11.1 \%(\mathrm{n}=32)$ completed diploma. We noticed that $(70.9 \%)$ were staff nurses, and $17.3 \%$ of nurses had 5 to 10 years of experience. 
Table 1. Characteristics of participants' demographics.

\begin{tabular}{|c|c|}
\hline & Total \\
\hline & $\mathrm{N}=289$ \\
\hline Age in years & $34.3(8.2)$ \\
\hline \multicolumn{2}{|l|}{ Gender } \\
\hline Male & $67 / 289(23.2 \%)$ \\
\hline Female & $222 / 289(76.8 \%)$ \\
\hline \multicolumn{2}{|l|}{ Marital status } \\
\hline single & $63 / 289(21.8 \%)$ \\
\hline married & $225 / 289(77.9 \%)$ \\
\hline divorced & $1 / 289(0.3 \%)$ \\
\hline \multicolumn{2}{|c|}{ Years of Experience in Nursing Research } \\
\hline No experience & $120 / 289(41.5 \%)$ \\
\hline less than 5 & $119 / 289(41.2 \%)$ \\
\hline $5-10$ years & $50 / 289(17.3 \%)$ \\
\hline \multicolumn{2}{|l|}{ Position in HMC } \\
\hline staff nurse & $205 / 289(70.9 \%)$ \\
\hline charge Nurse & $32 / 289(11.1 \%)$ \\
\hline head nurse & $13 / 289(4.5 \%)$ \\
\hline CNS & $32 / 289(11.1 \%)$ \\
\hline others & $7 / 289(2.4 \%)$ \\
\hline \multicolumn{2}{|c|}{ Highest education level } \\
\hline Doctorate & $3 / 289(1.0 \%)$ \\
\hline Master's degree & $58 / 289(20.1 \%)$ \\
\hline Bachelor's degree & $196 / 289(67.8 \%)$ \\
\hline Diploma & $32 / 289(11.1 \%)$ \\
\hline
\end{tabular}

More than half of the participants agreed that $51.6 \%, 47.0 \%$, and $55.3 \%$ of barriers to implementation of evidence-based Practice are related to organizational, research, and individual aspects, respectively. The obstacles of evidencebased practice (EBP) by nurses, research-related, and organizational aspects are presented in Table 2.

The lack of time for research (shortage of time) (66.9\%), lack of authority to change the patient care procedure at work (63.7\%), feels lack of benefits to change the Practice (54.6\%) and uncertainty regarding whether to believe the results of the research (54.2\%) are the most important individual barriers.

The most important research related barriers to implementation of EBP are lack of knowledge to understand the statistical analysis (58.6\%), relevant literature not being compiled in one location (53.0\%), lack of research information (55.4\%), and feeling incapable of evaluating the quality of the research (52.0\%). 
Table 2. BARRIER Scale items.

\begin{tabular}{|c|c|}
\hline & Mean $\pm \mathrm{SDn} / \mathrm{N}(\%)$ \\
\hline \multicolumn{2}{|l|}{ Nurse (Individual) related factors } \\
\hline The Nurse does not have time to read the research. & $1.9(0.9)$ \\
\hline No extent & $16 / 281(5.7 \%)$ \\
\hline little extent & $77 / 281(27.4 \%)$ \\
\hline moderate/great extent & $188 / 281(66.9 \%)$ \\
\hline The Nurse feels the benefits of changing Practice will be minimal & $1.6(1.0)$ \\
\hline No extent & $54 / 282(19.1 \%)$ \\
\hline little extent & $74 / 282(26.2 \%)$ \\
\hline moderate/great extent & $154 / 282(54.6 \%)$ \\
\hline The Nurse is uncertain whether to believe the results of the research & $1.6(1.1)$ \\
\hline No extent & $56 / 277(20.2 \%)$ \\
\hline little extent & $71 / 277(25.6 \%)$ \\
\hline moderate/great extent & $150 / 277(54.2 \%)$ \\
\hline The Nurse does not feel she/he has enough authority to change the patient care process & $1.9(1.0)$ \\
\hline No extent & $32 / 278(11.5 \%)$ \\
\hline little extent & $69 / 278(24.8 \%)$ \\
\hline moderate/great extent & $177 / 278(63.7 \%)$ \\
\hline The Nurse sees research results are little benefit for self & $1.5(1.1)$ \\
\hline No extent & $62 / 276(22.5 \%)$ \\
\hline little extent & $77 / 276(27.9 \%)$ \\
\hline moderate/great extent & $137 / 276(49.6 \%)$ \\
\hline The Nurse does not see the value of research for practice & $1.4(1.2)$ \\
\hline No extent & $88 / 271(32.5 \%)$ \\
\hline little extent & $53 / 271(19.6 \%)$ \\
\hline moderate/great extent & $130 / 271(48.0 \%)$ \\
\hline The Nurse is unwilling to change/try new ideas in Practice & $1.3(1.2)$ \\
\hline No extent & $109 / 289(37.7 \%)$ \\
\hline little extent & $58 / 289(20.1 \%)$ \\
\hline moderate/great extent & $48 / 289(16.6 \%)$ \\
\hline The patient is not willing to accept the treatment or a procedure based on quality research & $1.6(1.2)$ \\
\hline No extent & $62 / 261(23.8 \%)$ \\
\hline little extent & $68 / 261(26.1 \%)$ \\
\hline moderate/great extent & $131 / 261(50.2 \%)$ \\
\hline \multicolumn{2}{|l|}{ Research related factors } \\
\hline Research Implications for Practice are not made clear & $1.6(1.1)$ \\
\hline No extent & $48 / 270(17.8 \%)$ \\
\hline little extent & $97 / 270(35.9 \%)$ \\
\hline moderate/great extent & $125 / 270(46.3 \%)$ \\
\hline
\end{tabular}


B. Al-Lenjawi et al.

\section{Continued}

Statistical analyses are not understandable

$1.7(1.0)$

No extent

40/273 (14.7\%)

little extent

$73 / 273(26.7 \%)$

moderate/great extent

$160 / 273(58.6 \%)$

The research is not relevant to the Nurse's Practice

$1.3(1.2)$

No extent

$101 / 276(36.6 \%)$

little extent

$63 / 276(22.8 \%)$

moderate/great extent

$112 / 276(40.6 \%)$

The research has methodological inadequacies

$1.5(1.2)$

No extent

$64 / 262(24.4 \%)$

little extent

$85 / 262(32.4 \%)$

moderate/great extent

$113 / 262(43.1 \%)$

The relevant literature is not compiled in one place

$1.7(1.1)$

No extent

$51 / 268(19.0 \%)$

little extent

75/268 (28.0\%)

moderate/great extent

$142 / 268(53.0 \%)$

The conclusions drawn from the research are not justified to Practice

$1.5(1.1)$

No extent

$60 / 275$ (21.8\%)

little extent

80/275 (29.1\%)

moderate/great extent

$135 / 275(49.1 \%)$

The literature reports conflicting results

$1.6(1.1)$

No extent

$45 / 269(16.7 \%)$

little extent

$103 / 269$ (38.3\%)

moderate/great extent

$121 / 269(45.0 \%)$

The research is not reported clearly and readably

$1.5(1.1)$

No extent

$71 / 275(25.8 \%)$

little extent

75/275 (27.3\%)

moderate/great extent

129/275 (46.9\%)

The amount of research information is overwhelming

$1.8(1.1)$

No extent

$39 / 267(14.6 \%)$

little extent

$80 / 267(30.0 \%)$

moderate/great extent

148/267 (55.4\%)

The Nurse does not feel capable of evaluating the quality of the research

$1.6(1.1)$

No extent

$58 / 275(21.1 \%)$

little extent

$74 / 275(26.9 \%)$

moderate/great extent

$143 / 275(52.0 \%)$ 


\section{Continued}

English Language is Used in research is difficult to understand

$0.9(1.1)$

No extent

$143 / 280(51.1 \%)$

little extent

$61 / 280(21.8 \%)$

moderate/great extent

$76 / 280(27.1 \%)$

\section{Organizational factors}

Research reports/articles are not readily available. $1.5(1.1)$

No extent

$58 / 277(20.9 \%)$

little extent

$83 / 277(30.0 \%)$

moderate/great extent

$136 / 277(49.1 \%)$

The facilities are inadequate for implementation of research result in Practice

$1.4(1.1)$

No extent

69/274 (25.2\%)

little extent

$89 / 274(32.5 \%)$

moderate/great extent

$116 / 274(42.3 \%)$

The Nurse feels results are not generalizable to own setting.

$1.5(1.0)$

No extent

$47 / 274(17.2 \%)$

little extent

99/274 (36.1\%)

moderate/great extent

$128 / 274(46.7 \%)$

The Nurse is isolated from knowledgeable colleagues with whom to discuss the research

$1.7(1.1)$

No extent

$50 / 277(18.1 \%)$

little extent

67/277 (24.2\%)

moderate/great extent

$160 / 277(57.8 \%)$

Physicians will not cooperate with implementation of result in Practice

$1.7(1.1)$

No extent

$47 / 277(17.0 \%)$

little extent

$82 / 277(29.6 \%)$

moderate/great extent

$148 / 277(53.4 \%)$

There is not a documented need to change Practice

$1.5(1.1)$

No extent

$68 / 275(24.7 \%)$

little extent

$73 / 275(26.5 \%)$

moderate/great extent

$134 / 275(48.7 \%)$

Other staff is not supportive of implementation of study result $1.6(1.1)$

No extent

$51 / 277(18.4 \%)$

little extent

$85 / 277(30.7 \%)$

moderate/great extent

$141 / 277(50.9 \%)$

There is insufficient time on the job to implement new ideas $1.9(1.0)$

No extent

$33 / 278(11.9 \%)$

little extent

$67 / 278(24.1 \%)$

moderate/great extent

$178 / 278(64.0 \%)$ 


\section{Continued}

\begin{tabular}{lc}
\hline My Organization is less motivating nurses to use findings in nursing practice & $1.4(1.2)$ \\
\hline No extent & $72 / 289(28.4 \%)$ \\
little extent & $72 / 289(24.9 \%)$ \\
moderate/great extent & $115 / 289(39.8 \%)$ \\
\hline Inadequate facility to access up to date research resources (Library, Journals) & $1.5(1.1)$ \\
\hline No extent & $67 / 289(23.2 \%)$ \\
little extent & $74 / 289(25.6 \%)$ \\
moderate/great extent & $135 / 289(46.7 \%)$ \\
\hline Training is not adequate by the Organization to use research findings in my clinical Practice & $1.7(1.2)$ \\
\hline No extent & $54 / 289(18.7 \%)$ \\
little extent & $71 / 289(24.6 \%)$ \\
moderate/great extent & $147 / 289(50.9 \%)$ \\
\hline I don't have access to expert Nursing research Staff in the Organization & $1.8(1.2)$ \\
\hline No extent & $50 / 289(17.3 \%)$ \\
little extent & $71 / 289(24.6 \%)$ \\
Moderate/great extent & $147 / 289(50.9 \%)$ \\
\hline
\end{tabular}

In terms of organizational barrier, the most common factor was insufficient time on the job to implement new ideas (64.0\%), nurse is isolated from knowledgeable colleagues with whom to discuss the research (57.8\%) and thinking physicians will not cooperate with the implementation of result in practice (53.9\%) also inadequate training and not having expert research staff in facility reported was (50.9\%).

The main barriers to using research evidence in nursing practice among nurses working in HMC were items appearing under research related (mean 13.9). BARRIER Scale items in rank order by each factor score are summarised in Table 2.

Table 3 demonstrates the associations between demographic variables and barriers to implementation of evidence-based practice by individual, research, and organizational aspects. There was a statistical and significant correlation between education level $(\mathrm{P}=0.018)$, gender $(\mathrm{p}=0.05$ considered as significant), and barriers to implementation of evidence-based practice experienced by nurses associated with organizational aspects.

Barriers to implementation of evidence-based practice experienced by nurses associated with individual $(\mathrm{p} \leq 0.001)$ and research $(\mathrm{p} \leq 0.047)$ aspects, only gender was significant respectively.

Table 4 shows the association between each item of different evidence-based Practices, i.e., individual, research, and organizational aspects and designation (clinical nurse specialist (CNS) vs. others). In terms of Nurse related parts, we found the patient is not willing to accept the treatment or procedure based on quality research result factor was having higher barrier with staff nurse, charge nurse, and head Nurse compared to CNS (mean 1.4; $\mathrm{p}=0.004$ ). 
Table 3. Associations between demographic variables and implementation of evidence-based Practice by individual, research and organizational aspects.

\begin{tabular}{|c|c|c|c|c|c|}
\hline & & & Nursing barrier & Research barrier & Organization barrier \\
\hline \multirow{3}{*}{ Gender } & Male & $\mathrm{N}=67$ & $13.3(5.0)$ & $15.6(7.5)$ & $12.6(5.9)$ \\
\hline & Female & $\mathrm{N}=222$ & $10.6(5.1)$ & $13.4(8.0)$ & $11.0(5.8)$ \\
\hline & $\mathrm{p}$-value & & $<0.001$ & 0.047 & 0.05 \\
\hline \multirow{3}{*}{ Marital status } & Single & $\mathrm{N}=63$ & $10.3(5.6)$ & $12.4(9.1)$ & $10.7(6.5)$ \\
\hline & Married & $\mathrm{N}=225$ & $11.5(5.1)$ & $14.3(7.6)$ & $11.6(5.7)$ \\
\hline & p-value & & 0.25 & 0.13 & 0.53 \\
\hline \multirow{4}{*}{ Years of Experience } & No experience & $\mathrm{N}=120$ & $10.7(4.9)$ & $13.5(7.5)$ & $10.7(5.7)$ \\
\hline & less than 5 & $\mathrm{~N}=119$ & $11.4(5.3)$ & $13.4(8.1)$ & $11.8(5.9)$ \\
\hline & 5 - 10 years & $\mathrm{N}=50$ & $12.3(5.4)$ & $16.1(8.5)$ & $12.3(5.9)$ \\
\hline & p-value & & 0.16 & 0.094 & 0.18 \\
\hline \multirow{6}{*}{ Position in HMC } & Staff nurse & $\mathrm{N}=205$ & $11.1(5.2)$ & $14.1(8.1)$ & $11.2(5.9)$ \\
\hline & Charge nurse & $\mathrm{N}=32$ & $11.7(5.0)$ & $13.3(7.5)$ & $10.4(5.9)$ \\
\hline & Head nurse & $\mathrm{N}=13$ & $13.7(4.4)$ & $15.8(8.4)$ & $12.4(6.6)$ \\
\hline & CNS & $\mathrm{N}=32$ & $10.5(6.0)$ & $12.1(7.8)$ & $13.2(5.3)$ \\
\hline & others & $\mathrm{N}=7$ & $12.6(3.6)$ & $16.4(3.0)$ & $12.1(4.6)$ \\
\hline & p-value & & 0.36 & 0.5 & 0.34 \\
\hline \multirow{5}{*}{$\begin{array}{l}\text { Highest level of } \\
\text { nursing education }\end{array}$} & Doctorate & $\mathrm{N}=3$ & $8.0(2.0)$ & $4.3(3.5)$ & $3.7(2.3)$ \\
\hline & Master's degree & $\mathrm{N}=58$ & $11.3(5.5)$ & $13.4(7.8)$ & $12.9(5.2)$ \\
\hline & Bachelor's degree & $\mathrm{N}=196$ & $11.4(5.2)$ & $14.4(8.0)$ & $11.2(5.9)$ \\
\hline & Diploma & $\mathrm{N}=32$ & $10.4(4.5)$ & $12.7(7.4)$ & $10.5(6.0)$ \\
\hline & p-value & & 0.55 & 0.1 & 0.018 \\
\hline
\end{tabular}

Table 4. Difference between CNS and others (staff nurses, charge nurse, and head nurses) and implementation of evidence-based Practice by the individual, research, and organizational aspects.

\begin{tabular}{|c|c|c|c|}
\hline Factor & $\begin{array}{l}\text { Staff nurse, charge nurse, } \\
\text { and Head Nurse }\end{array}$ & CNS & p-value \\
\hline \multirow[t]{2}{*}{$\mathrm{N}$} & 257 & \multicolumn{2}{|l|}{32} \\
\hline & Mean (SD) & \multicolumn{2}{|l|}{ Mean (SD) } \\
\hline The Nurse does not have time to read the research & $1.8(0.8)$ & $1.9(0.9)$ & 0.42 \\
\hline The Nurse feels the benefits of changing Practice will be minimal & $1.5(1.0)$ & $1.5(1.0)$ & 0.97 \\
\hline The Nurse is uncertain whether to believe the results of the research & $1.5(1.0)$ & $1.5(1.0)$ & 0.99 \\
\hline $\begin{array}{l}\text { The Nurse does not feel she/he has enough authority to change the patient care } \\
\text { process }\end{array}$ & $1.8(1.0)$ & $1.8(1.1)$ & 0.81 \\
\hline The Nurse sees research results are little benefit for self & $1.5(1.0)$ & $1.2(1.1)$ & 0.15 \\
\hline The Nurse does not see the value of research for practice & $1.3(1.0)$ & $1.2(1.1)$ & 0.69 \\
\hline
\end{tabular}




\section{Continued}

The Nurse is unwilling to change/try new ideas in Practice

$1.2(1.1)$

$0.9(1.0) \quad 0.21$

The patient is not willing to accept the treatment or

a procedure based on quality research results

Overall Nursing barrier

Research Implications for Practice are not made clear

Statistical analyses are not understandable

$1.4(1.0)$

$0.9(0.9) \quad 0.004$

The research is not relevant to the Nurse's Practice

The research has methodological inadequacies

The relevant literature is not compiled in one place

The conclusions drawn from the research are not justified to Practice

$1.3(5.1)$

$10.5(6.0) \quad 0.41$

The literature reports conflicting results

$1.4(0.9)$

$1.3(1.1) \quad 0.57$

$1.6(0.9)$

$1.3(1.1) \quad 0.042$

$1.1(1.0)$

$1.1(1.0) \quad 0.72$

$1.3(0.9)$

$1.0(1.0) \quad 0.15$

$1.5(0.9)$

$1.5(1.1) \quad 0.76$

$1.4(0.9)$

$1.0(0.9) \quad 0.031$

The research is not reported clearly and readably

$1.4(0.9)$

$1.0(0.8) \quad 0.010$

$1.4(1.0)$

$1.0(1.0) \quad 0.041$

The amount of research information is overwhelming

$1.6(0.9)$

$1.4(1.0) \quad 0.37$

The Nurse does not feel capable of evaluating the quality of the research

$1.5(1.0)$

$1.2(1.1) \quad 0.053$

The English Language is Used in research is difficult to understand

$0.8(1.0)$

$0.8(1.1) \quad 0.91$

Overall Research barrier

Research reports/articles are not readily available.

$14.1(8.0)$

$12.1(7.8) 0.18$

$1.4(0.9)$

$1.5(1.2) \quad 0.82$

The facilities are inadequate for the implementation of research result in Practice

$1.3(1.0)$

$1.6(0.8) \quad 0.11$

The Nurse feels results are not generalizable to own setting.

$1.4(0.8)$

$1.5(1.0) \quad 0.58$

The Nurse is isolated from knowledgeable colleagues with whom to discuss the research.

Physicians will not cooperate with the implementation of results in Practice

There is not a documented need to change Practice

$6(1.0)$

$1.8(1.0) \quad 0.12$

$1.5(1.0)$

$1.9(1.0) \quad 0.021$

Another staff is not supportive of the implementation of study result

$1.4(1.0)$

$1.4(1.0) \quad 0.78$

$1.5(1.0)$

$1.7(1.2) \quad 0.36$

There is insufficient time on the job to implement new ideas

$1.8(1.0)$

$2.0(1.0) \quad 0.23$

$1.4(1.1)$

$1.4(1.0) \quad 0.76$

$1.5(1.1)$

$1.8(1.1) \quad 0.071$

Inadequate facility to access up to date research resources (Library, Journals)

$1.6(1.1)$

$1.8(1.0) \quad 0.40$

Practice

I don't have access to expert Nursing research Staff in the Organization

$1.7(1.1)$

$1.3(1.0) \quad 0.034$

Overall Organization barrier
$19.5(7.8) \quad 0.18$

The staff nurse, charge nurse, and head nurses reported that difficulty in understanding the statistical analysis (mean 1.6; $\mathrm{p}=0.04$ ), conclusions drawn from the research are not justified to practice (mean 1.4; $\mathrm{p}=0.03$ ), literature reports conflicting results (mean 1.4; $\mathrm{p}=0.01$ ) and the research is not reported clearly and readably (mean 1.4; $\mathrm{p}=0.04$ ) as compared to CNS which is statistically significant in terms of research barriers. For the organizational factors, the barrier was significantly higher in terms of physicians will not cooperate with the im- 
plementation of results in Practice (mean 1.9; $\mathrm{p}=0.02$ ) in CNS as compared to staff nurses, charge nurses, and head nurses.

The communication gap between physicians and nurses, insufficient resources for research, staff resistance or behaviors towards changing the practice, and inaccessibility of a group or team to coordinate the research ideas, were other reporting barriers to implementing the Evidence-Based Practices.

Participants highlighted the factors that can promote the evidence-based practice was develop core committee consisting of expert persons to discuss ideas for improvement, availability of trained researchers in the unit, Motivation, and support from the leaders to conduct research, training, and education for research and EBP, Promote more research studies from own facility, Monthly journal clubs and clinical teachings about recent findings and Evidence of clinical practices.

\section{Discussion}

The self-reporting from the questionnaire by the nurses shows that a lot of work is still needed to implement the EBP in the Hamad medical corporation in QATAR. More than 36.6\% of respondents reported that they hardly ever sought the research that is not relevant to the Nurse's Practice. Some of the reasons given for not using research were the same as in many other studies [15] [16] [17].

Additionally, it was found that more than half of the respondents were not familiar with the term EBP. It is evident that there are many factors for this. Some of these, such as literature not being compiled in one place, insufficient time on the job to implement new ideas, and lack of support from administration and physicians, are problems that are common in many healthcare organizations.

In this study, major evidence-based barriers were found to be most often related to organizational factors. Insufficient time was reported as a significant barrier; hence attention needs to be given to techniques to improve nurses' time management. The finding is supported by other studies as well [17] [18] [19]. A reason for insufficient time on the job could be that most nursing practices are more conventional based rather than Evidence-based, resulting in the increased workload. However, it could also be due to poor time management.

The study identifies five main barriers to research utilization were insufficient time on the job to implement new ideas, not enough time to read the research, not enough authority to change patient care procedures, nurses being unaware of research, and not being able to understand the statistical analysis. The reported barriers are consistent with the other studies [20] [21] [22].

Unfamiliarity with statistical and research terminology could be a serious barrier for nurses with undergraduate Nurses who might not be sufficiently exposed to such terminologies. A well-designed training program may likely overcome these problems to some extent. 
An apparent deficiency of many studies on this topic was inadequate coverage given to information-related competencies. As medical and health care literature is growing exponentially, all health care professionals, including nurses, need to acquire good searching skills to quickly retrieve current and accurate information. Inadequate search skills can result in missing crucial information or retrieving too much information that could cause information overload and anxiety [23].

There are many ways of increasing nurses' knowledge, including introducing in-service research classes and conducting professional development sessions during the overlapping time between Shifts, and providing a project day for clinical nurses whose major role in updating the clinical guidelines and procedures may ultimately increase interest in developing evidence-based care.

\section{Recommendations}

Support, encouragement, availability of the research staff in the unit, and recognition from the management and administration were the most frequent facilitators for research utilization. A reward system may be needed to help profile innovative practice development achievements in healthcare to support and encourage the evidence-based practitioners. Nurses' research values, skills, and awareness are important factors that need to be considered. Educators can help nurses develop a positive self-image by providing them with theory and practical experience that encourages more independent function and allows them a professional role to provide unique and essential services to the community.

Nursing managers under HMC should encourage the development of head nurses in the field of research and evidence-based Practice. In training programs in nursing, we should include more knowledge in research and evidence-based Practice. The future national vision of nursing development should clearly include research and EBP and be incorporated at all levels of hospital care.

\section{Conclusion}

The finding from this study confirms that there is a range of barriers of concern to nurses, and these are consistent with results that have been reported in previous research internationally. To enhance EBP strategies should be placed to minimize barriers and improve the facilitators of research utilization. However, the findings from this study highlight the need for professional nursing development in the country.

\section{Funding}

The study was funded by the Medical Research Center of HMC, Qatar.

\section{Study Limitation}

The study was conducted in one Critical Care Nurses and Clinical Nurse/Midwife Specialists in the Hamad Medical Corporation, thus limiting the generalis- 
ability of findings in another category of nurses. However, the findings were like international studies cited. The questionnaire was self-reported and did not capture the actual practices related to EBP implementation.

\section{Conflicts of Interest}

The authors declare no conflicts of interest regarding the publication of this paper.

\section{References}

[1] Khammarnia, M., Haj Mohammadi, M., Amani, Z., Rezaeian, S. and Setoodehzadeh, F. (2015) Barriers to Implementation of Evidence-Based Practice in Zahedan Teaching Hospitals, Iran, 2014. Nursing Research and Practice, 2015, Article ID: 357140. https://doi.org/10.1155/2015/357140

[2] Plathe, H., Solheim, E. and Eide, H. (2021) Nursing Students' and Preceptors' Experiences with Using an Assessment Tool for Feedback and Reflection in Supervision of Clinical Skills: A Qualitative Pilot Study. Nursing Research and Practice, 2021, Article ID: 5551662. https://doi.org/10.1155/2021/5551662

[3] Tahir, S., et al. (2017) Nurses' Awareness, Perception, and Barriers for Implementation of Evidence-Based Practices at Govt. Hospital Lahore. Saudi Journal of Medical and Pharmaceutical Sciences, 3, 615-621.

[4] Nsemo, A.D., John, M.E., Etifit, R.E., Mgbekem, M.A. and Oyira, E.J. (2013) Clinical Nurses' Perception of Continuing Professional Education as a Tool for Quality Service Delivery in Public Hospitals Calabar, Cross River State, Nigeria. Nurse Education in Practice, 13, 328-334. https://doi.org/10.1016/j.nepr.2013.04.005

[5] Yoder, L.H., Kirkley, D., McFall, D.C., Kirksey, K.M., StalBaum, A.L. and Sellers, D. (2014) CE: Original Research: Staff Nurses' Use of Research to Facilitate EvidenceBased Practice. American Journal of Nursing, 114, 26-37. https://doi.org/10.1097/01.NAJ.0000453753.00894.29

[6] Shalala, D., Bolton, L., Bleich, M., Brennan, T., Campbell, R. and Devlin, L. (2011) The Future of Nursing: Leading Change, Advancing Health. The National Academy Press, Washington DC.

[7] Kajermo, K.N., Undén, M., Gardulf, A., Eriksson, L.E., Orton, M.L., Arnetz, B.B., et al. (2008) Predictors of Nurses' Perceptions of Barriers to Research Utilization. Journal of Nursing Management, 16, 305-314.

[8] Oh, E.G. (2008) Research Activities and Perceptions of Barriers to Research Utilization among Critical Care Nurses in Korea. Intensive and Critical Care Nursing, 24, 314-322. https://doi.org/10.1016/j.iccn.2007.12.001

[9] Squires, J.E., Estabrooks, C.A., Gustavsson, P. and Wallin, L. (2011) Individual Determinants of Research Utilization by Nurses: A Systematic Review Update. Implementation Science, 6, Article No. 1. https://doi.org/10.1186/1748-5908-6-1

[10] Agbedia, C., Okoronkwo, I., Onokayeigho, E. and Agbo, M.A. (2014) Nurses' Perspective of the Research-Practice Gap in Nursing. Open Journal of Nursing, 4, 95-100. https://doi.org/10.4236/ojn.2014.42013

[11] Cheraghi, M.A., Salsali, M. and Safari, M. (2010) Ambiguity in Knowledge Transfer: The Role of the Theory-Practice Gap. Iranian Journal of Nursing and Midwifery Research, 15, 155-166.

[12] Brown, C.E., Wickline, M.A., Ecoff, L. and Glaser, D. (2009) Nursing Practice, Know- 
ledge, Attitudes and Perceived Barriers to Evidence-Based Practice at an Academic Medical Center. Journal of Advanced Nursing, 65, 371-381.

[13] Chijindu, A., Samantha, E. and Augusta, E. (2016) Evaluation of Barriers to the Implementation of Evidence-Based Practice (EBP) among Nurses Working at Federal Teaching Hospital Abakaliki (FETHA II). International Journal of Nursing, Midwife and Health Related Cases, 2, 71-90.

[14] Bahadori, M., Raadabadi, M., Ravangard, R. and Mahaki, B. (2016) The Barriers to the Application of the Research Findings from the Nurses' Perspective: A Case Study in a Teaching Hospital. Journal of Education and Health Promotion, 5, Article No. 14. https://doi.org/10.4103/2277-9531.184553

[15] Ashley, J.S. (2005) Barriers and Facilitators to Research Utilization as Perceived by Critical Care Nurses. University of California, San Francisco.

[16] Hutchinson, A.M. and Johnston, L. (2004) Bridging the Divide: A Survey of Nurses' Opinions Regarding Barriers to, and Facilitators of, Research Utilization in the Practice Setting. Journal of Clinical Nursing, 13, 304-315.

[17] Retsas, A. and Nolan, M. (1999) Barriers to Nurses' Use of Research: An Australian Hospital Study. International Journal of Nursing Studies, 36, 335-343.

[18] Hicks, C. (1998) Barriers to Evidence-Based Care in Nursing: Historical Legacies and Conflicting Cultures. Health Services Management Research, 11, 137-147.

[19] McColl, A., Smith, H., White, P. and Field, J. (1998) General Practitioners' Perceptions of the Route to Evidence-Based Medicine: A Questionnaire Survey. British Medical Journal, 316, 361-365. https://doi.org/10.1136/bmj.316.7128.361

[20] Cheng, Z.J. and Shan, J. (2020) 2019 Novel Coronavirus: Where We Are and What We Know. Infection, 48, 155-163. https://doi.org/10.1007/s15010-020-01401-y

[21] Clarkson, J. (2004) Getting Research into Clinical Practice-Barriers and Solutions. Caries Research, 38, 321-324. https://doi.org/10.1159/000077772

[22] Jansen, M.W., Van Oers, H.A., Kok, G. and De Vries, N.K. (2010) Public Health: Disconnections between Policy, Practice, and Research. Health Research Policy and Systems, 8, Article No. 37. https://doi.org/10.1186/1478-4505-8-37

[23] Theng, Y.L., Chang, Y.K., Mokhtar, I.A., et al. (2011) Adopting Evidence-Based Practice in Clinical Decision-Making Nurses' Perceptions, Knowledge, and Barriers. Journal of the Medical Library Association, 99, 229-236. https://doi.org/10.3163/1536-5050.99.3.010 


\section{Abbreviations}

EBP, Evidence-Based Practice

CNS/CMS, Clinical Nurse/Midwife Specialists

HMC, Hamad Medical Corporation

NHS, National Health Services.

WWRC, Women's Wellness Research Center

\section{Appendix}

\section{Questionnaire}

\section{Barriers to Evidence-Based Practice}

We would like to know the extent to which you think each of the following situations is a barrier to nurses' use of research in to enhance their Practice.

If you currently hold a position in a clinical site, please answer the questions in relation to your current work settings. If you do not currently Practice, you may refer to your Last clinical Experience or provide your general perceptions.

For each item, circle the number of the response that best represents your view. Thank you for sharing your views with us.

\section{Demographic Data}

1. Age in completed years:

2. Gender:

Male $\square$ Female $\square$

3. Marital status:

$\square$ Single

$\square$ Married

$\square$ Divorced

$\square$ Widow

4. Position in HMC:

$\square$ Staff Nurse.

$\square$ Charge Nurse

$\square$ Head Nurse

$\square$ Clinical Nurse Specialist.

$\square$ Others

5. Years of Experience in Nursing Research:

$\square$ No experience

$\square$ less than 5

$\square 5-10$

$\square$ years above

6. What is your highest level of nursing education?

$\square$ Doctorate

$\square$ Master's degree

$\square$ Bachelor's degree

$\square$ Associate degree

$\square$ Diploma 


\section{Nurse Related Barrier}

\begin{tabular}{lllll} 
No & A little & \multicolumn{2}{l}{ Moderate Great } & No \\
Extent & Extent & Extent & Extent & Opinion \\
$(0)$ & $(1)$ & $(2)$ & $(3)$ & $(4)$
\end{tabular}

1 The Nurse does not have time to read the research

2 The Nurse feels the benefits of changing Practice will be minimal.

3 The Nurse is uncertain whether to believe the results of the research.

4

The Nurse does not feel they have enough authority to change patient care procedures.

5

The Nurse sees research results are little benefit for

self

6

The Nurse does not see the value of research for

practice

7

The Nurse is unwilling to change/try new ideas in

practice

The patient is not willing to accept the treatment or a procedure based on the quality research result

\section{Research related barrier}

9 Research Implications for Practice are not made clear.

10 Statistical analyses are not understandable.

11 The research is not relevant to the Nurse's Practice.

12 The research has methodological inadequacies.

13 The relevant literature is not compiled in one place.

14 The conclusions drawn from the research are not justified to Practice

15 The literature reports conflicting results

16 The research is not reported clearly and readably.

17 The amount of research information is overwhelming.

18 The Nurse does not feel capable of evaluating the quality of the research

19 The English Language is Used in research is difficult to understand

\section{Organizational barriers}

20 Research reports/articles are not readily available.

21

The facilities are inadequate for the implementation of research result in

Practice

22 The Nurse feels results are not generalizable to own setting.

The Nurse is isolated from knowledgeable colleagues with whom to discuss the research

24 Physicians will not cooperate with the implementation of results in Practice

25 There is not a documented need to change Practice.

26 Another staff is not supportive of the implementation of study result

27 There is insufficient time on the job to implement new ideas

28 My Organization is less motivating nurses to use findings in nursing practice 


\section{Continued}

29 Inadequate facility to access up to date research resources (Library, Journals)

30 Training is not adequate by the Organization to use research findings in my clinical Practice

31 I don't have access to expert Nursing research Staff in the Organization.

32. Which of the above items do you feel are the three most significant barriers to Evidence-based Practices?

Greatest Barrier................................................... Item \#:

Second Greatest Barrier........................................ Item \#:

Third Greatest Barrier.......................................... Item \#:

33. What are the factors you think to facilitate Evidence-Based Practices? 